\title{
Endovascular coiling versus neurosurgical clipping in patients with unruptured intracranial aneurysm: a systematic review
}

\author{
Jin Seub Hwang ${ }^{1}$, Min Kyung Hyun ${ }^{1 *}$, Hyun Joo Lee ${ }^{1}$, Ji Eun Choi ${ }^{1}$, Jong Hee Kim, Na Rae Lee ${ }^{1}$,
} Jin-Won Kwon ${ }^{1,2}$ and EnJu Lee ${ }^{1}$

\begin{abstract}
Background: To compare the effects of endovascular coiling and neurosurgical clipping in patients with unruptured intracranial aneurysm.

Methods: Sixteen electronic databases were searched for articles published between 1950 and July 2010 to compare clinical outcomes of clipping and coiling. Researchers reviewed all searched articles and extracted data independently. The quality of studies and evidence were evaluated using MINORS and GRADEprofiler, respectively. The odds ratio (OR) was calculated using the inverse variance meta-analysis method for each study outcome. To assess heterogeneity of ORs across cohorts, Cochran's Q statistic and $I^{2}$ were used.

Results: Of 4160 studies, 24 were identified $(n=31865)$. Clipping resulted in significantly higher disability using the Glasgow Outcome Scale (OR, 2.38; 95\% Cl, 1.33-4.26) and Modified Rankin Scale (OR, 2.83; 95\% Cl, 1.42-5.63) when compared with coiling. ORs for complications were also higher with clipping (ORs for neurological and cardiac complications were 1.94 with a $95 \%$ confidence interval [Cl] of $1.09-3.47$ and 2.51 with a $95 \% \mathrm{Cl}$ of 1.15-5.50). Clipping resulted in significantly greater disability in the short term $(\leq 6 \mathrm{~m})(\mathrm{OR}$ on the Glasgow Outcome Scale, 2.72; 95\% Cl, 1.16-6.34), but not in the long term (>6 m)(OR for Glasgow Outcome Scale, 2.12; 95\% Cl, 0.93-4.84).

Conclusions: Coiling was a better procedure for treatment of unruptured intracranial aneurysm in terms of disability, complications, especially in the short term. Because of the limitations of the reviewed studies, further studies are required to support the present results.
\end{abstract}

Keywords: Unruptured intracranial aneurysm, Endovascular coiling, Neurosurgical clipping

\section{Background}

Recent developments in non-invasive imaging detection, such as magnetic resonance (MR) angiography and computed tomography (CT) angiography, have made screening for unruptured intracranial aneurysm (UIA) possible in the general population [1]. Despite study results showing that it is not cost-effective to screen for asymptomatic UIA [2], such screening has become widespread, and UIA is being identified with increasing frequency.

Patients with UIA always have risks of rupture with intracranial aneurysms. A nationwide study in Sweden

\footnotetext{
* Correspondence: mk3three@gmail.com

'National Evidence-based Healthcare Collaborating Agency, Changkyung B/D 8 F, 28-7 Wonnam-dong, Seoul, Jongno-gu 110-450, Korea

Full list of author information is available at the end of the article
}

showed that the 5-, 10- and 15-year risks of death after subarachnoid haemorrhage (SAH) were $12.9 \%, 23.6 \%$ and $35.4 \%$, respectively [3]. Thus, patients with UIA are often treated to prevent $\mathrm{SAH}$, and these prophylactic treatments include neurosurgical clipping and endovascular coiling. Neurosurgical clipping of the aneurysm was the standard treatment prior to the introduction of detachable coils, but endovascular coiling has recently been increasing [4]. Neurosurgical clipping is recommended over endovascular coiling for young patients and for small or anterior circulation aneurysms, i.e., lowrisk cases [5]. Neurosurgical clipping is an order of magnitude more durable than endovascular coiling, but endovascular coiling is less invasive than neurosurgical

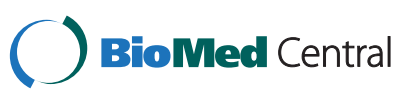


clipping; thus, it may be suitable for high-risk UIA patients (elderly or posterior aneurysms, etc.) [5].

Using the national inpatient sample database from 2002 to 2008, Smith et al. [6] showed that the majority of ruptured and unruptured aneurysms in the US are coiled. However, which treatment is better remains controversial, and there have been no systematic reviews of patients with UIA. Therefore, an extensive systematic review and meta-analysis were performed to compare the benefits and risks in UIA patients treated with endovascular coiling vs. neurosurgical clipping.

\section{Methods}

\section{Literature search}

We developed and adhered to a protocol for population, intervention, comparison and outcome (PICO) search methods, data extraction, quality assessment, metaanalysis and grading of the quality of the evidence for this systematic review.

Articles Published before July 2010 in 16 electronic databases were searched. These databases included three international databases, ten Korean domestic databases and three Japanese domestic databases: (1) Ovid-Medline, (2) Ovid-Embase, (3) Cochrane Library, (4) KISS (http:// kiss.kstudy.com), (5) KMBASE (http://kmbase.medric.or. kr), (6) KoreaMed (http://www.koreamed.org), (7) NDSL (http://www.ndsl.kr), (8) KiSTi (http://society.kisti. re. kr), (9) J Cerebrovasc Surg (http://jkcvs.ksevs.org), (10)
J Korean Soc Radiol (http://www.radiology.or.kr), (11) J Korean Neurosurg Soc (http://jkns.or.kr), (12) Neuro intervention (http://www.ksin.or.kr), (13) Korean J Stroke (http://www.stroke.or.kr), (14) JAMAS (http:// www.jamas.or.jp), (15) Medical online (http://www. meteo-intergate.com) and (16) J-stage (http://www. jstage.jst.go.jp). Various combinations of Mesh headings and keywords were used, such as "intracranial aneurysm", "subarachnoid haemorrhage", "embolisation", "neurosurgical procedures", "neurosurgery", "unruptured", "coil", "Guglielmi", "GDC", and "clip". The search was limited to human studies without language restrictions.

\section{Study selection, data extraction and quality assessment}

Eligible studies were those that included adult ( $\geq 18$ years) patients with UIA. Patients with mycotic, infectious, dissecting or fusiform aneurysms, arteriovenous malformation or arteriovenous fistula were excluded. Case series, case reports and publications that had not undergone peer review were excluded. In addition, studies were required to have directly comparable outcome measures for endovascular coiling and neurosurgical clipping, such as overall death, in-hospital mortality, disability and complications. Disability was regarded as a score of $1-5$ on the Modified Rankin Scale [mRS] and a score of 2-4 on the Glasgow Outcome Scale [GOS]. The mRS, a clinician-reported measure of global disability, is widely applied to evaluate stroke patient outcomes, and scores

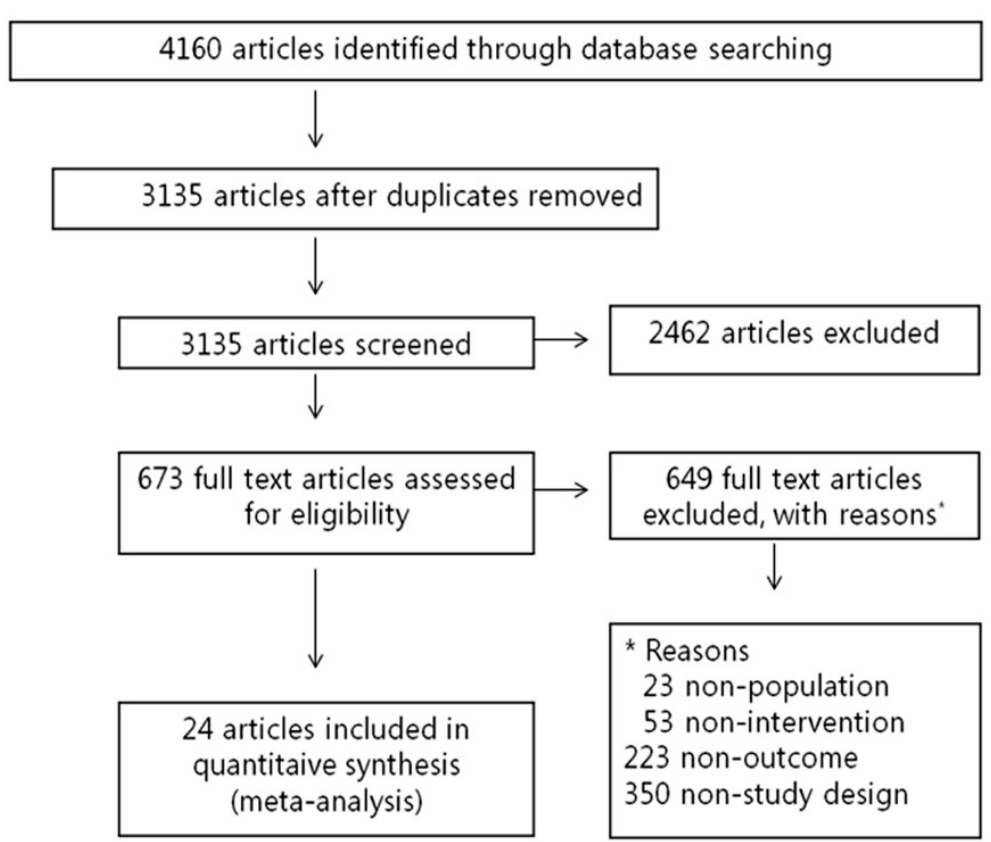

Figure 1 Flow diagram of article selection for this study. 
run from no symptoms at all (score 0) to death (score 6) [7]. The GOS assesses outcome after severe brain damage and runs from death (score 1) to good recovery (score 5) [8]. There were various complications, including bleeding or haematoma in the brain, ischemia or infarction, cerebral vessel damage, cerebrospinal fluid fistula, infection, cranial nerve disorder, cognitive impairment, encephalitis, meningitis, embolism, cardiac disease and pulmonary disease.

Four authors (HJL, JEC, JSH and MKH) independently reviewed all searched articles and extracted data using pre-made extraction forms that included study design, follow-up period, inclusion/exclusion criteria, sample size, sex, age, aneurysm location, aneurysm size, race, baseline characteristics, treatment protocol, outcome variables and complications. Disability was calculated based on the percentages of categories other than death/ good recovery in mRS/GOS. The numbers of events for outcomes were extracted according to the intention-totreat principle.

Six authors (HJL, JEC, JHK, JSH, LRL and MKH) independently evaluated the quality of the studies using the Methodological Index for Nonrandomised Studies (MINORS) [9]. In the case of disagreement, consensus was reached through discussion and negotiations with partners. If a consensus could not be achieved within the group, a third party was involved, and then an agreement was reached by majority rule.

\section{Meta-analysis and grading the quality of the evidence}

A meta-analysis was performed to synthesise the outcomes, except for missing data among 24 articles. Binary outcomes were expressed as odds ratios (ORs). The reporting methods for in-hospital mortality were diverse, including the number of patients, unadjusted ORs and adjusted ORs. Therefore, lnOR and standard error were calculated using statistical equations.

Fixed and random effects inverse-variance meta-analysis was used to combine the studies and obtain the average effects and 95\% confidence intervals (CI). The subgroup analyses were performed by outcome measurement times (short time, $\leq 6$ months; long time, $>6$ months) according to medical experts' opinions.

To assess heterogeneity across studies, funnel plots were visually examined, and Cochran's $Q$ statistic and the $I^{2}$ statistic were used. Publication bias was also assessed using funnel plots, Begg and Mazumdar's rank correlation (Begg's test) and Egger's linear regression asymmetry test of the intercept (Egger's test). Finally, the quality of the body of evidence was graded as "high", "moderate", "low", or "very low" [10].

Table 1 Meta-analysis of neurosurgical clipping vs. endovascular coiling for each outcome

\begin{tabular}{|c|c|c|c|c|c|c|}
\hline Outcome & $\begin{array}{c}\text { Studies, } \\
n\end{array}$ & $\begin{array}{c}\text { Patients, } \\
n\end{array}$ & $\begin{array}{c}\text { Random effects, } \\
\text { OR }(95 \% \mathrm{Cl})\end{array}$ & $\begin{array}{c}\text { Fixed effects, } \\
\text { OR }(95 \% \mathrm{Cl})\end{array}$ & $\mathrm{I}^{2}, \% *$ & $\begin{array}{l}\text { Heterogeneity } \\
P^{*}\end{array}$ \\
\hline \multicolumn{7}{|l|}{ Overall death } \\
\hline Overall & 5 & 1967 & $1.42(0.50,4.04)$ & $1.42(0.50,4.04)$ & 0 & 0.69 \\
\hline$\leq 6$ months measurement time & 4 & 1950 & $1.25(0.42,3.74)$ & $1.25(0.42,3.74)$ & 0 & 0.65 \\
\hline \multicolumn{7}{|l|}{ In-hospital mortality } \\
\hline Overall & 5 & & $1.55(0.91,2.61)$ & $1.35(1.07,1.70)$ & 52 & 0.08 \\
\hline Adjusted OR & 3 & & $3.35(0.91,12.30)$ & $3.46(2.20,5.44)$ & 83 & 0.003 \\
\hline \multicolumn{7}{|l|}{ Disability (GOS) } \\
\hline Overall & 9 & 754 & $2.38(1.33,4.26)$ & $2.38(1.33,4.26)$ & 0 & 0.99 \\
\hline$\leq 6$ months measurement time & 4 & 314 & $2.72(1.16,6.34)$ & $2.72(1.16,6.34)$ & 0 & 0.81 \\
\hline$>6$ months measurement time & 4 & 331 & $2.12(0.93,4.84)$ & $2.12(0.93,4.84)$ & 0 & 0.90 \\
\hline Asian races & 4 & 413 & $2.41(1.19,4.90)$ & $2.41(1.19,4.90)$ & 0 & 0.84 \\
\hline Western races & 5 & 341 & $2.32(0.84,6.39)$ & $2.32(0.84,6.39)$ & 0 & 0.92 \\
\hline \multirow[t]{2}{*}{ Disability (mRS) } & 2 & 262 & $2.83(1.42,5.63)$ & $2.83(1.42,5.63)$ & 0 & 0.81 \\
\hline & & & & & 0 & 0.72 \\
\hline \multicolumn{7}{|l|}{ Complication } \\
\hline Cerebral haemorrhage & 8 & 7419 & $1.96(0.83,4.64)$ & $1.44(1.03,2.02)$ & 63 & 0.01 \\
\hline Cerebral infarction & 12 & 7635 & $1.07(0.69,1.66)$ & $0.96(0.74,1,23)$ & 39 & 0.08 \\
\hline Neurological complication & 11 & 7661 & $1.94(1.09-3.47)$ & $1.38(1.12,1.71)$ & 58 & 0.009 \\
\hline Cardiac complication & 6 & 7067 & $2.51(1.15 .5 .50)$ & $2.51(1.15 .5 .50)$ & 0 & 0.98 \\
\hline
\end{tabular}


Meta-analyses were conducted using Comprehensive Meta-analysis 2.0 (Biostat, Englewood, NJ, USA), and the quality of evidence and strength of recommendation were graded using GRADEprofiler 3.2.2 (GRADE Working Group).

\section{Results}

The authors independently reviewed titles and abstracts of 3135 identified unique studies; 2462 studies were excluded. The full-text publications of the remaining 673 potentially eligible studies were reviewed in detail. Of these, 645 were excluded based on the inclusion and exclusion criteria (Figure 1). Of 1581 international studies, 1480 Korean domestic studies and 1099 Japanese domestic studies, 24 observational studies reporting data from 31865 patients were selected for the comprehensive meta-analysis. Characteristics of these studies are presented in Additional file 1 and the quality of studies are listed in Additional file 1.

\section{Meta-analysis}

Four outcome types (disability measured by $\mathrm{mRS}$ and GOS, neurological and cardiac complications) showed statistically significant differences between coiling and clipping (Table 1, Figure 2, Figure 3). Clipping had significantly higher disability as measured by GOS (OR, 2.38; 95\% CI, 1.33-4.26) and mRS (OR, 2.83; 95\% CI, 1.42-5.63) when compared with coiling. ORs for neurological (OR, 1.94; 95\% CI, 1.09-3.47) and cardiac (OR, 2.51; 95\% CI, 1.15-5.50) complications were also higher with clipping.

On the other hand, overall mortality, in-hospital mortality and complications of cerebral haemorrhage and cerebral infarction showed no statistically significant differences between the two groups. There was evidence of

\section{(A) Overall death}

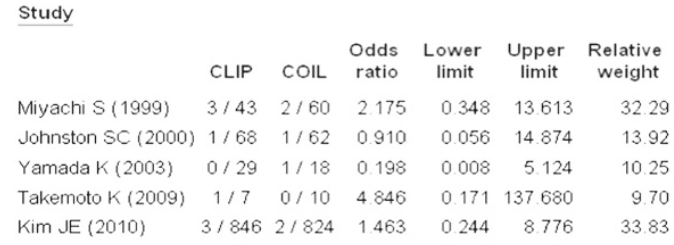

(B) In-hospital mortality

$$
\text { Study }
$$

$\begin{array}{lccrr} & \begin{array}{c}\text { Odds } \\ \text { ratio }\end{array} & \begin{array}{c}\text { Lower } \\ \text { limit }\end{array} & \begin{array}{c}\text { Upper } \\ \text { limit }\end{array} & \begin{array}{r}\text { Relative } \\ \text { weight }\end{array} \\ \text { Johnston SC (1999) } & 5.954 & 0.821 & 43.186 & 6.05 \\ \text { Johnston SC (2001) } & 6.619 & 1.611 & 27.198 & 10.48 \\ \text { Wiebers DO (2003) } & 0.850 & 0.386 & 1.874 & 21.90 \\ \text { Barker FG (2004) } & 1.300 & 0.602 & 2.808 & 22.44 \\ \text { Hoh BL (2010) } & 1.313 & 1.009 & 1.707 & 39.14 \\ & 1.546 & 0.914 & 2.614 & \end{array}$

(C) Disability measured by the Glasgow Outcome Scale

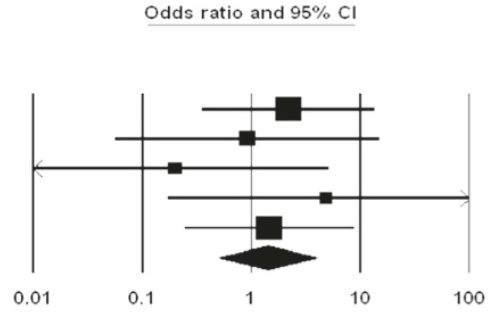

Odds ratio and $95 \% \mathrm{Cl}$

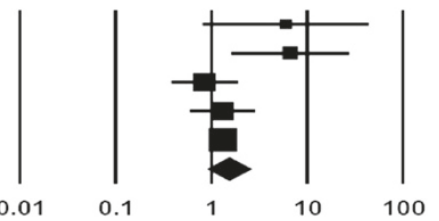

Study

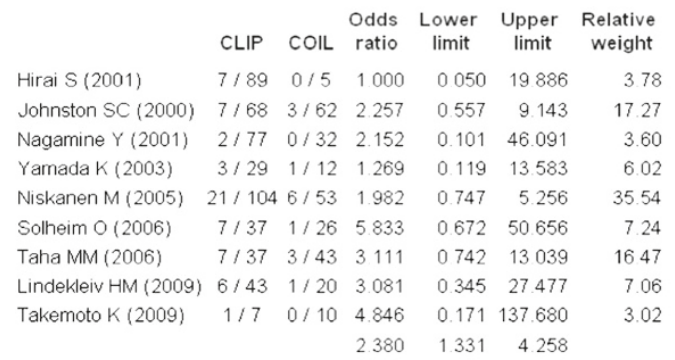

Odds ratio and $95 \% \mathrm{Cl}$

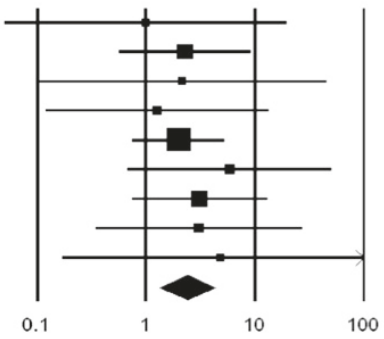

Figure 2 Outcomes from neurosurgical clipping vs. endovascular coiling. 
statistical heterogeneity, and the $\mathrm{I}^{2}$ range was $39 \%$ to $83 \%$, which represents moderate or substantial heterogeneity. Therefore, overall mortality, in-hospital mortality and complications of cerebral haemorrhage and cerebral infarction were incorporated into a randomeffects model.
In subgroup analysis by outcome-measurement time, clipping showed significantly higher disability measured by GOS (OR, 2.72; 95\% CI, 1.16-6.34) in the short term $(\leq 6 \mathrm{~m})$. However, disability (GOS) was not significantly different in the long term $(>6 \mathrm{~m})(\mathrm{OR}, 2.12 ; 95 \% \mathrm{CI}$, 0.93-4.84) (Table 1).

(A) Cerebral haemorrhage (complications)

\begin{tabular}{lccccccr} 
Study & \multicolumn{2}{c}{ Exposed / Total } & & & & \\
& CLIP & COIL & $\begin{array}{c}\text { Odds } \\
\text { ratio }\end{array}$ & $\begin{array}{c}\text { Lower } \\
\text { limit }\end{array}$ & $\begin{array}{c}\text { Upper } \\
\text { limit }\end{array}$ & $\begin{array}{r}\text { Relative } \\
\text { weight }\end{array}$ \\
Johnston SC (2000) & $2 / 68$ & $0 / 62$ & 4.699 & 0.221 & 99.817 & 6.34 \\
Nagamine Y (2001) & $4 / 77$ & $0 / 32$ & 3.980 & 0.208 & 76.092 & 6.70 \\
Kamiyama K (2003)4/235 & $0 / 51$ & 2.002 & 0.106 & 37.771 & 6.75 \\
Barker FG (2004) & $78 / 3498$ & $16 / 421$ & 0.577 & 0.334 & 0.998 & 27.88 \\
Solheim O (2006) & $1 / 37$ & $0 / 26$ & 2.178 & 0.085 & 55.584 & 5.77 \\
Higashida (2007) & $142 / 1881$ & $22 / 654$ & 2.346 & 1.483 & 3.709 & 28.85 \\
Iwamuro Y (2007) & $8 / 78$ & $0 / 54$ & 13.142 & 0.742232 .710 & 6.98 \\
Seifert V (2008) & $6 / 165$ & $1 / 80$ & 2.981 & 0.353 & 25.190 & 10.73 \\
& $245 / 603939 / 1380$ & 1.959 & 0.828 & 4.635 &
\end{tabular}

(B) Cerebral infarction (complications)

\begin{tabular}{|c|c|c|c|c|c|c|}
\hline \multirow[t]{2}{*}{$\underline{\text { Study }}$} & \multicolumn{2}{|c|}{ Cases / Total } & \multirow[b]{2}{*}{$\begin{array}{l}\text { Odds } \\
\text { ratio }\end{array}$} & \multirow[b]{2}{*}{$\begin{array}{c}\text { Lower } \\
\text { limit }\end{array}$} & \multirow[b]{2}{*}{$\begin{array}{c}\text { Upper } \\
\text { limit }\end{array}$} & \multirow[b]{2}{*}{$\begin{array}{c}\text { Relative } \\
\text { weight }\end{array}$} \\
\hline & CLIP & COIL & & & & \\
\hline Miyachi S (1999) & $11 / 43$ & $7 / 63$ & 2.750 & 0.970 & 7.799 & 10.98 \\
\hline Nagamine $Y(2001)$ & $1 / 77$ & $2 / 32$ & 0.197 & 0.017 & 2.258 & 2.91 \\
\hline Kamiyama K (2003) & $4 / 235$ & $2 / 51$ & 0.424 & 0.076 & 2.381 & 5.28 \\
\hline Vindlacheruvu RR (2003 & 03) $5 / 29$ & $1 / 26$ & 5.208 & 0.566 & 47.902 & 3.44 \\
\hline Yamada K (2003) & $1 / 32$ & $0 / 16$ & 1.571 & 0.061 & 40.754 & 1.70 \\
\hline Barker FG & $251 / 3498$ & $41 / 421$ & 0.716 & 0.506 & 1.013 & 24.54 \\
\hline Solheir & $3 / 37$ & $1 / 26$ & 2.206 & 0.216 & 22.476 & 3.17 \\
\hline Higashida RT (2007) & $79 / 1881$ & $18 / 654$ & 1.549 & 0.921 & 2.605 & 20.59 \\
\hline Iwamuro Y (2007) & $9 / 78$ & $4 / 54$ & 1.630 & 0.475 & 5.594 & 8.80 \\
\hline Cha JH (2008) & $3 / 58$ & $1 / 10$ & 0.491 & 0.046 & 5.253 & 3.06 \\
\hline Seifert V $(20$ & $10 / 165$ & $9 / 80$ & 0.509 & 0.198 & 1.307 & 12.37 \\
\hline Lindekleiv HM (2009) & $3 / 46$ & $1 / 23$ & 1.535 & 0.151 & 15.630 & 3.17 \\
\hline
\end{tabular}

(C) Neurological complications

\begin{tabular}{lcccccr} 
Study & \multicolumn{2}{c}{ Cases / Total } & & \multicolumn{3}{c}{ Statistics for each study } \\
\cline { 2 - 6 } & CLIP & COIL & $\begin{array}{c}\text { odds } \\
\text { ratio }\end{array}$ & $\begin{array}{c}\text { Lower } \\
\text { limit }\end{array}$ & $\begin{array}{c}\text { Upper } \\
\text { limit }\end{array}$ \\
Miyachi S (1999) & $3 / 43$ & $0 / 63$ & 10.975 & 0.552 & 218.095 \\
Johnston SC (2000) & $44 / 68$ & $13 / 62$ & 6.910 & 3.142 & 15.199 \\
Nagamine Y (2001) & $3 / 77$ & $0 / 32$ & 3.054 & 0.153 & 60.828 \\
Karniyama K (2003) & $2 / 235$ & $0 / 49$ & 1.060 & 0.050 & 22.422 \\
Yanada K (2003) & $4 / 32$ & $3 / 16$ & 0.619 & 0.121 & 3.176 \\
Barker FG (2004) & $274 / 3498$ & $21 / 421$ & 1.619 & 1.026 & 2.554 \\
Manabe H (2004) & $2 / 75$ & $0 / 15$ & 1.054 & 0.048 & 23.066 \\
Solheim O (2006) & $3 / 37$ & $0 / 26$ & 5.377 & 0.266 & 108.660 \\
Higashida (2007) & $266 / 1881$ & $86 / 654$ & 1.088 & 0.838 & 1.413 \\
Iwarnuro Y (2007) & $1 / 78$ & $0 / 54$ & 2.110 & 0.084 & 52.765 \\
Seifert V (2008) & $1 / 165$ & $0 / 80$ & 1.468 & 0.059 & 36.439 \\
& & & 1.382 & 1.118 & 1.709
\end{tabular}

(D) Cardiac complications
Odds ratio and $95 \% \mathrm{Cl}$

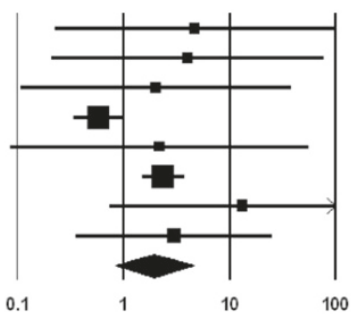

Odds ratio and $95 \% \mathrm{Cl}$

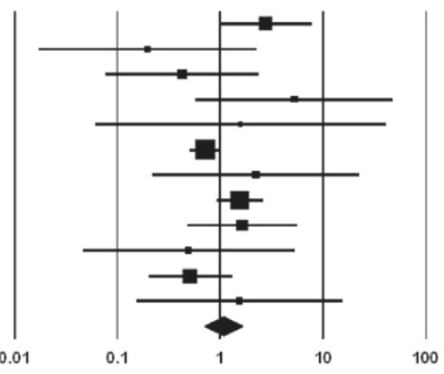

Odds ratio and $95 \% \mathrm{Cl}$

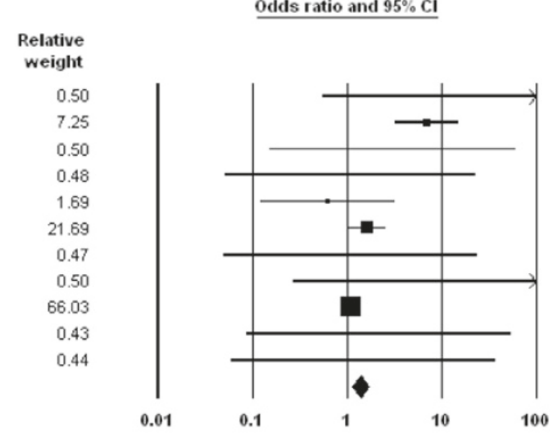

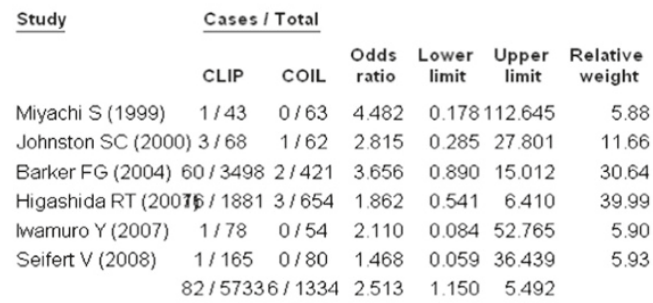

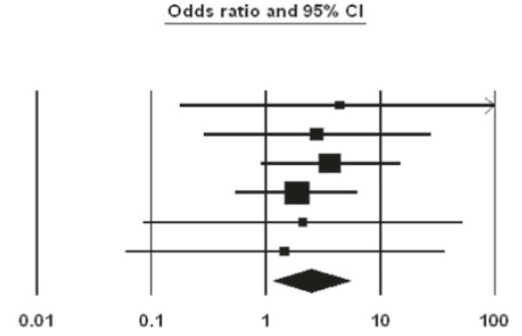

Figure 3 Outcomes from neurosurgical clipping vs. endovascular coiling (complications). 
We found no apparent systematic bias in the overall and subgroup meta-analyses, as assessed by a funnel plot and test (Table 2).

\section{Additional analysis}

The re-intervention rate for endovascular coiling was $2 \%$ to $15.4 \%$ in five studies. Coil compaction within the follow-up period is a common cause in most cases. In contrast, only two clipping studies reported reintervention; the rate of neurosurgical clipping was $0 \%$ in one study and $2.3 \%$ in the other.

\section{Discussion}

This study showed that coiling is associated with less harm than clipping in terms of disability measured by mRS and GOS, neurological and cardiac complications, but all of the studies included were observational. It is difficult to randomise controlled trials of surgical intervention in terms of such factors; consequently, observational studies may be the best available evidence. This is the first comprehensive systematic review and metaanalysis comparing clipping and coiling in patients with UIA. King et al. [11] and Raaymakers et al. [12] found mortality rates of $1.0 \%$ and $2.6 \%$ and morbidity rates of $4.1 \%$ and $10.9 \%$, respectively, in meta-analyses of the outcome of clipping for UIA. Ontario [13] performed a systematic review on the outcome of clipping for intracranial aneurysms including UIA. These previous studies were systematic reviews of only a single intervention and did not compare interventions with one another. Therefore, the present study is meaningful despite some limitations.

Sixteen accessible electronic databases were searched, including major international databases and Korean and Japanese domestic databases without language restriction. The aneurismal subarachnoid haemorrhage incidence rate in Japan is more than double those in other regions [14], so Japanese domestic databases were included in the search.

After an extensive search and review, 24 studies were identified ( $n=31$ 865) among 4160 studies. Clipping

Table 2 Publication-bias test

\begin{tabular}{lcc}
\hline Outcome & Egger Test $\boldsymbol{P}$-value & Begg Test $\boldsymbol{P}$-value \\
\hline Overall death & 0.5762 & 1.000 \\
In-hospital mortality & 0.3218 & 0.4624 \\
Disability (GOS) & 0.7071 & 0.9170 \\
Complication & & \\
Cerebral haemorrhage & 0.4102 & 0.9015 \\
Cerebral infarction & 0.5302 & 0.6312 \\
Neurological complication & 0.2501 & 0.8763 \\
Cardiac complication & 0.8927 & 0.7071 \\
\hline
\end{tabular}

resulted in significantly higher disability as measured by GOS (overall and short-term $[\leq 6 \mathrm{~m}]$ ), but this significant difference between the two groups disappeared over the long term $(>6 \mathrm{~m})$. Clipping is considered a type of craniotomy and a more invasive treatment than coiling. Therefore, patients may suffer short-term and/or longterm disability as a result of surgery. However, some of these disabilities may disappear over time with healing and therapy.

Clipping had 2-2.5 times as many neurological complications and cardiac complications than coiling. The major complication differed based on the treatment method; for example, ischemic injury caused by vasoocclusion and vasoconstriction during surgery was common in clipping, whereas thromboembolism caused by the endovascular procedure and procedure-related rupture during endovascular therapy were common in coiling.

However, although the cause of ischemic or haemorrhagic brain injury differed, the types of injury were similar (ischemic or haemorrhagic). Therefore, these complications were directly compared between the clipping and coiling groups. No significant differences were found between clipping and coiling in the present study. However, another study using the national impatient sample database showed that in-hospital deaths and perioperative complications (i.e., intracerebral haemorrhage and acute ischemic stroke) were higher with clipping than with coiling [15].

This study had several limitations. First, the selected studies were all observational, because we did not find any well-designed, prospective, randomised comparative clinical trials. Therefore, the levels of evidence for all outcomes were "very low" in keeping with the quality of evidence assessment dictated by GRADEprofiler. Second, the analysis did not examine outcomes according to the size and location of aneurysms. The information about size/location of aneurysms in the selected studies was either not found or was useless because treatment outcomes were not reported for each size and location.

\section{Conclusions}

In conclusion, endovascular coiling has benefits in UIA treatment in terms of low disability after treatment in the short term and fewer complications compared with neurosurgical clipping. However, because most of the reviewed studies were retrospective cohort studies, further well-designed, prospective, randomised comparative clinical trials are required to verify these results.

\section{Additional file}

Additional file 1: Characteristics of identified publications. 


\section{Competing interests}

The author(s) declare that we have no competing interests.

\section{Authors' contributions}

MKH, Draft the protocol. M K H, JEC, Develop a search strategy. MKH, JEC, Search for articles. NRL, EJL, Obtain copies of articles. HJL, JEC, JSH,MKH, Select which articles to include. HJL, JEC, JSH,MKH, Extract data from articles. HJL, JEC, JHK, JSH, NRL, MKH, Evaluate the quality of articles. MKH, JSH, Carry out the analysis. MKH, JSH, Interpret the analysis. MKH, JSH, JWK, Draft the final review. MKH, Update the review. All authors read and approved the final manuscript.

\section{Acknowledgements}

This study was funded by the National Evidence-based Healthcare Collaborating Agency (NECA), project no. NA2010-012.

\section{Author details}

'National Evidence-based Healthcare Collaborating Agency, Changkyung B/D 8 F, 28-7 Wonnam-dong, Seoul, Jongno-gu 110-450, Korea. ${ }^{2}$ Kyungpook National University, 80 Daehakro, Daegu, Bukgou 702-701, Korea.

Received: 29 November 2011 Accepted: 18 September 2012 Published: 22 September 2012

\section{References}

1. Byun HS: Recent trends in the treatment of cerebral aneurysms: comparison between endovascular coil embolization and surgical clipping. Neurointervention 2009, 4:1-5.

2. Yoshimoto $Y$, Wakai S: Cost-effectiveness analysis of screening for asymptomatic, unruptured intracranial aneurysms. A mathematical model. Stroke 1999, 30(8):1621-1627.

3. Nieuwkamp DJ, Algra A, Blomqvist P, Adami J, Buskens E, Koffijberg H, Rinkel GJ: Excess mortality and cardiovascular events in patients surviving subarachnoid hemorrhage: a nationwide study in Sweden. Stroke 2011, 42(4):902-907.

4. Van Der Schaaf I, Algra A, Wermer M, Molyneux A, Clarke M, Van Gijn J, Rinkel G: Endovascular coiling versus neurosurgical clipping for patients with aneurysmal subarachnoid haemorrhage. Cochrane Database Syst Rev 2005, 19(4):CD003085.

5. Komotar RJ, Mocco J, Solomon RA: Guidelines for the surgical treatment of unruptured intracranial aneurysms: the first annual J. Lawrence pool memorial research symposium--controversies in the management of cerebral aneurysms. Neurosurgery 2008, 62(1):183-193. discussion 193-184.

6. Smith GA, Dagostino P, Maltenfort MG, Dumont AS, Ratliff JK: Geographic variation and regional trends in adoption of endovascular techniques for cerebral aneurysms. J Neurosurg 2011, 114(6):1768-1777.

7. Banks JL, Marotta CA: Outcomes validity and reliability of the modified Rankin scale: implications for stroke clinical trials: a literature review and synthesis. Stroke 2007, 38(3):1091-1096.

8. Jennett B, Snoek J, Bond MR, Brooks N: Disability after severe head injury: observations on the use of the Glasgow Outcome Scale. J Neurol Neurosurg Psychiatry 1981, 44(4):285-293.

9. Slim K, Nini E, Forestier D, Kwiatkowski F, Panis Y, Chipponi J: Methodological index for non-randomized studies (minors): development and validation of a new instrument. ANZ J Surg 2003, 73(9):712-716.

10. In Cochrane handbook for systematic reviews of interventions version 5.1.0. The Cochrane Collaboration 2011. Edited by Higgins JPT, Green S. Available from www.cochrane-handbook.org.

11. King JT Jr, Berlin JA, Flamm ES: Morbidity and mortality from elective surgery for asymptomatic, unruptured, intracranial aneurysms: a meta-analysis. J Neurosurg 1994, 81(6):837-842.

12. Raaymakers TW, Rinkel GJ, Limburg M, Algra A: Mortality and morbidity of surgery for unruptured intracranial aneurysms: a meta-analysis. Stroke 1998, 29(8):1531-1538.

13. Secretariat MA: Coil embolization for intracranial aneurysms: an evidence-based analysis. Ontario Health Technology Assessment Series 2006, $6(1): 1-114$.
14. de Rooij NK, Linn FH, van der Plas JA, Algra A, Rinkel GJ: Incidence of subarachnoid haemorrhage: a systematic review with emphasis on region, age, gender and time trends. J Neurol Neurosurg Psychiatry 2007, 78(12):1365-1372.

15. Alshekhlee A, Mehta S, Edgell RC, Vora N, Feen E, Mohammadi A, Kale SP, Cruz-Flores S: Hospital mortality and complications of electively clipped or coiled unruptured intracranial aneurysm. Stroke 2010, 41(7):1471-1476.

doi:10.1186/1471-2377-12-99

Cite this article as: Hwang et al:: Endovascular coiling versus neurosurgical clipping in patients with unruptured intracranial aneurysm: a systematic review. BMC Neurology 2012 12:99.

\section{Submit your next manuscript to BioMed Central and take full advantage of:}

- Convenient online submission

- Thorough peer review

- No space constraints or color figure charges

- Immediate publication on acceptance

- Inclusion in PubMed, CAS, Scopus and Google Scholar

- Research which is freely available for redistribution 